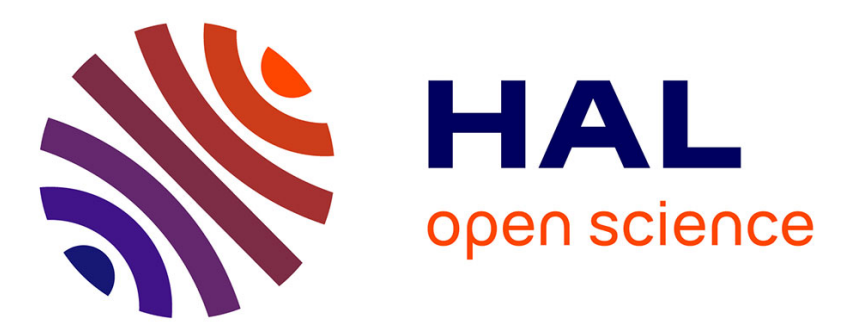

\title{
Characterisation of Pulsed Laser Deposited Bi Doped Dy Iron Garnet Thin Films on GGG(111), GGG(110), YSZ(100) and $\operatorname{Si}(100)$
}

\author{
P. Papakonstantinou, B. Teggart, R. Atkinson
}

\section{- To cite this version:}

P. Papakonstantinou, B. Teggart, R. Atkinson. Characterisation of Pulsed Laser Deposited Bi Doped Dy Iron Garnet Thin Films on GGG(111), GGG(110), YSZ(100) and Si(100). Journal de Physique IV Proceedings, 1997, 07 (C1), pp.C1-475-C1-476. 10.1051/jp4:19971192 jpa-00254842

HAL Id: jpa-00254842

https://hal.science/jpa-00254842

Submitted on 1 Jan 1997

HAL is a multi-disciplinary open access archive for the deposit and dissemination of scientific research documents, whether they are published or not. The documents may come from teaching and research institutions in France or abroad, or from public or private research centers.
L'archive ouverte pluridisciplinaire HAL, est destinée au dépôt et à la diffusion de documents scientifiques de niveau recherche, publiés ou non, émanant des établissements d'enseignement et de recherche français ou étrangers, des laboratoires publics ou privés. 


\title{
Characterisation of Pulsed Laser Deposited Bi Doped Dy Iron Garnet Thin Films on GGG(111), GGG(110), YSZ(100) and Si(100)
}

\author{
P. Papakonstantinou, B. Teggart and R. Atkinson \\ Physics Department, Queen's University of Belfast, Belfast BT7 INN, U.K.
}

\begin{abstract}
Bi and Ga substituted Dy iron garnet films ( $\sim 350 \mathrm{~nm}$ thick) have been pulsed laser deposited on single crystalline GGG (111), GGG (110), YSZ (100) and Si (100) substrates at a background pressure of 0.1 mbar and substrate temperature in the range of $550-590^{\circ} \mathrm{C}$. Epitaxial growth was obtained only in the case of GGG substrates. Growth on the other substrates resulted in randomly oriented polycrystalline layers. However, in all cases the films exhibited perpendicular anisotropy and Kerr blue spectra of comparable magnitude. The magnetic anisotropy was explained in terms of in plane tensile stress induced by the difference in thermal expansion coefficients between substrate and film. The magneto-optical (MO) behaviour in the $250-900 \mathrm{~nm}$ wavelength range, on the first three substrates was consistent with theoretical calculations based on the fundamental constants of BI:YIG thick films grown by LPE. MO studies for growth on Si suggested the presence of interfacial layers introduced by chemical reactions at the film/substrate interface.
\end{abstract}

\section{INTRODUCTION}

Current interest in Bi substituted Dy Iron Garnets for future ultra high density MO recording results from a rather unique combination of positive uniaxial anisotropy, large intrinsic MO activity and low optical loss in the visible wavelength region. Several approaches ( sol-gel, pyrolysis, sputtering ) to thin film synthesis of Bi based garnets have been reported. Common to many of these attempts were problems associated with maintaining composition, crystalline phase and good surface morphology. Pulsed laser deposition, (PLD) is emerging as a technique for deposition of multicomponent oxides..

In an earlier investigation [1] we have studied the preparation of epitaxial pulsed laser deposited $\mathrm{Bi}$ and $\mathrm{Ga}$ substituted $\mathrm{Dy}$ Iron garnet [(BiGa): DyIG] films on GGG (111) substrates. Many issues critical to the high quality of epitaxial garnet films have been addressed in this study. Of particular note, the Bi content was acutely sensitive to both substrate temperature and oxygen pressure. The results suggest that at elevated temperatures required to nucleate the garnet phase the oxygen background pressure must be sufficiently high in order to incorporate the volatile Bi substituents into the film. The observed improvement in $\mathrm{Bi}$ content at high oxygen pressures is most likely related to the formation of $\mathrm{Bi}$ oxides with lower vapour pressure than that of $\mathrm{Bi}$.

The present study is a continuation of previous efforts and is specifically directed on examining the effect of substrate type on the orientation, structure and MO properties of BiGa:DyIG films under constant growth conditions. The study focuses on BiGa: DyIG films deposited on GGG (111), GGG (110), Yttria Stabilised Zirconia (100), [YSZ, $\left(\mathrm{ZrO}_{2}\right)_{-x}\left(\mathrm{Y}_{2} \mathrm{O}_{2}\right)_{x}$ with $\mathrm{X}=0.09$ ], and $\mathrm{Si}(100)$ substrates at a background pressure of 0.1 mbar and substrate temperature of $550-590^{\circ} \mathrm{C}$

\section{EXPERIMENTAL PROCEDURES}

The PLD system has been described previously in more detail [1]. A KrF excimer laser $(\lambda=248 \mathrm{~nm}, \mathrm{FWHM}=25 \mathrm{~ns}, \mathrm{f}=10$ $\mathrm{Hz}$, focused to a fluence of $\sim 2 \mathrm{~J} / \mathrm{cm}^{2}$ ) was used to ablate a ceramic target with average composition $\mathrm{Bi}_{15} \mathrm{Dy}_{1.5} \mathrm{Fe}_{4} \mathrm{Ga}_{1} \mathrm{O}_{12}$. The laser ablated material was deposited onto the substrate positioned $3 \mathrm{~cm}$ away from the target. The substrate block temperature was $550-590^{\circ} \mathrm{C}$ and the oxygen partial pressure in the chamber was maintained at 0.1 mbar. Each deposition consisted of 10,000 pulses which resulted in films of $\sim 350 \mathrm{~nm}$ in thickness.

The Si (100) substrates were prepared by immersing them in dilute HF for $1 \mathrm{~min}$, and then rinsing in distilled water immediately before insertion into the deposition chamber. The first pulses were always made at the base pressure to avoid oxidation of the Si during the first stages of growth. 


\section{RESULTS AND DISCUSSION}

Figure 1 shows a representative X-ray $\Theta-2 \Theta$ scan of $350 \mathrm{~nm}$ thick films, grown on GGG (110) substrates. The split peaks at each position correspond to the substrate (higher intensity) and the garnet film (small angle site). Note that in the inset scan, both $\mathrm{Cu}-\mathrm{K} \alpha_{1}$ and $\mathrm{Cu}-\mathrm{K} \alpha_{2}$ lines are visible, a double peak corresponds to a single set of planes. Likewise, for growth on GGG (111) substrate the $\Theta-2 \Theta$ large angle scans (10-110 deg) consistently contained only 2 peaks: the (444) BiGa: DylG reflection and adjacent to it the (444) GGG reflection. This indicates that the films grown on GGG (111) and GGG (110) had a single garnet phase with [111] and [110] orientation respectively perpendicular to the film plane. These orientations are easy directions of magnetisation as evidenced by the square hysteresis polar Kerr effect loops obtained at $633 \mathrm{~nm}$.

It is speculated that the origin of the perpendicular anisotropy is magnetostriction. GGG (a = 12.383 $\mathrm{A}$ ) has a $\sim 1.4 \%$ smaller lattice parameter than BiGa: DyIG ( $a=12.555 \pm 0.005 \AA$ ). To accommodate this mismatch the initial growth must be strained. The in plane lattice constant will thus be reduced forcing the out of plane spacing to expand. At a critical film thickness part of the strain is relieved by the introduction of misfit dislocations. Assuming that the BiGa: DyIG grows in a strain free state at the deposition temperature then upon cooling to room temperature a tensile stress $(\sigma>0)$ will develop due to the different thermal expansion coefficients of the film $\left(\alpha_{\mathrm{f}} \sim 11.5 \times 10^{-5} /{ }^{\circ} \mathrm{C}\right)$ and the substrate $\left(\alpha_{3}=9.4 \times 10^{-6} /{ }^{\circ} \mathrm{C}\right)$. The stress induced anisotropies present in [111] and [110] oriented films can be expressed [2] respectively as:

for [111]: $\mathrm{K}_{u}=-\frac{3}{2} \sigma \lambda_{11}$ and for $[110]: \quad \mathrm{K}_{u}=-\frac{3}{4} \sigma\left(\lambda_{111}+\lambda_{100}\right), \quad \mathrm{K}_{i}=+\frac{3}{4} \sigma\left(\lambda_{100}-\lambda_{111}\right)$

where $\lambda_{\text {thl }}$ are the magnetostriction constants and $K_{u}$ and $K_{i}$ denote uniaxial and in plane anisotropy constants. The [111] and [110] orientations will be easy directions of magnetisation provided $K_{u}$ and $K_{u}+K_{i}$ are positive and their magnitudes are larger than the shape anisotropy. For Dy based garnets, the negative $\lambda_{\text {hks }}$ coupled with the in plane tensile stress induced by the difference in thermal expansion coefficients could give rise to the observed perpendicular anisotropy.
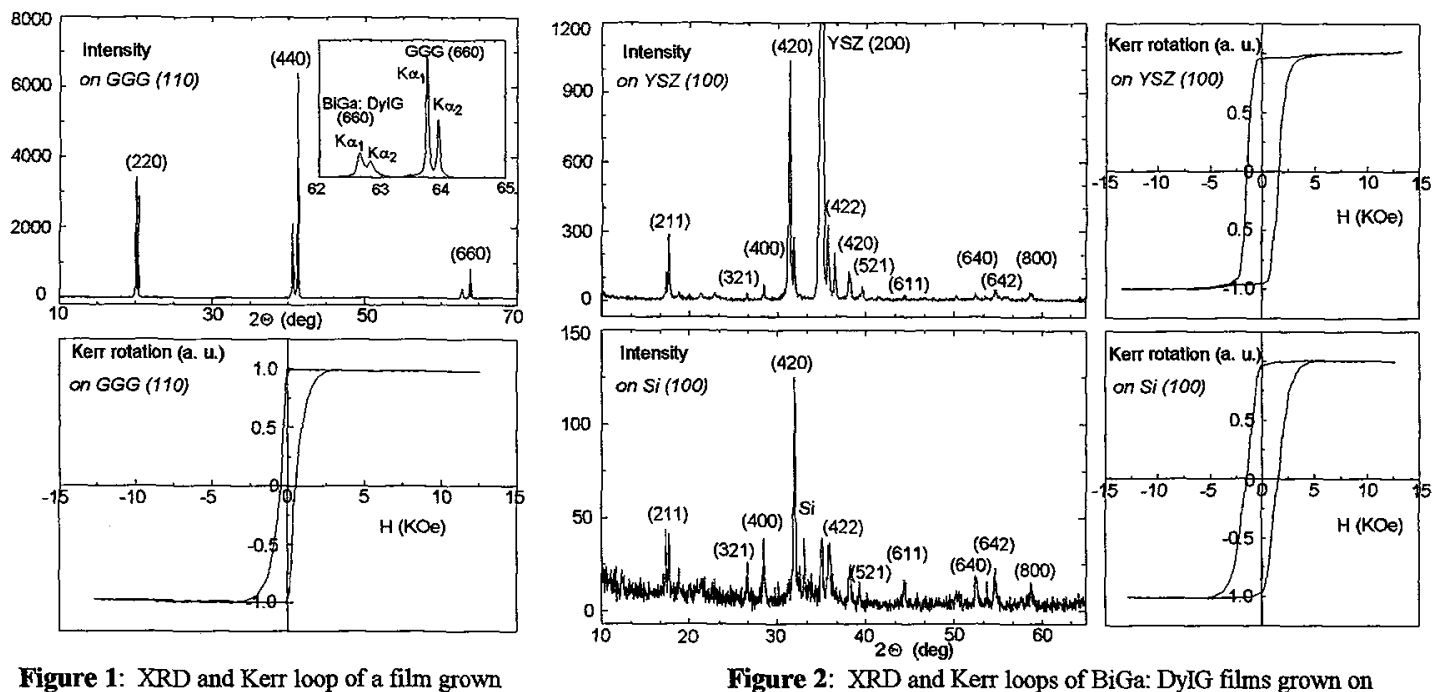

Figure 1: XRD and Kerr loop of a film grown on GGG (110).

$$
\text { YSZ (100) and } \mathrm{Si}(100) \text { substrates. }
$$

For growth on the lattice mismatched substrates such as $\operatorname{YSZ}(100)\left(\mathrm{a}=5.14 \AA, \alpha_{\mathrm{f}}=10.3 \times 10^{-6} /{ }^{\circ} \mathrm{C}\right)$ and $\mathrm{Si}(100)(\mathrm{a}=5.43 \AA$, $\left.\alpha_{\mathrm{f}}=3.8 \times 10^{-6} /{ }^{\circ} \mathrm{C}\right)$, X-ray diffraction identified the presence of randomly oriented polycrystalline garnet in addition to a small amount of other phases in these films (fig. 2). Both exhibited square hysteresis loops and Kerr blue spectra of similar magnitude to the corresponding oriented films on GGG. MO studies on the BiGa:DyIG/Si system suggested interdiffusion and chemical reaction at the film / substrate interface. The Kerr rotation and ellipticity spectra throughout the investigated wavelength region ( $250-900 \mathrm{~nm}$ ) for films on GGG and YSZ compared well with predictions based on the fundamental data of Bi:YIG thick films grown by LPE.

\section{References}

[1] P.Papakonstantinou, B. Teggart and R. Atkinson, to appear in J. Magn. Magn. Mater. (1996).

[2] D. J. Breed, A.B. Voermans, P.Q.J. Nederpel and B.A.H. van Bakel., J. Appl. Phys. 54 (1983) 1519-1527. 